\title{
UNIFORM CORROSION WASTAGE EFFECTS ON THE LOAD-CARRYING CAPACITY OF DAMAGED STEEL BEAMS
}

\author{
Yasser Sharifi \\ Department of Civil Engineering \\ Vali-e-Asr University of Rafsanjan, Rafsanjan, Iran \\ (Corresponding author: E-mail: y.sharifi@vru.ac.ir or yasser_sharifi@yahoo.com)
}

Received: 28 April 2011; Revised: 11 July 2011; Accepted: 21 July 2011

\begin{abstract}
The aim of the present study is to investigate the effects of uniform corrosion on the load-carrying capacity of steel beam sections. In this paper, a credible corrosion model for damaged steel beams has been developed based on the real existing data. Thickness loss data were compiled from corrosion damaged samples beams which picked up from a petrochemical industry. The developed deteriorated model was employed to demonstrate the effects of uniform corrosion on the structural behavior of damaged steel beams due to uniform corrosion wastage. It was found from the obtained results that the lateral distorsional buckling is the critical failure mode at the preliminary age of corrosion wastage.
\end{abstract}

Keywords: Corrosion, Steel structures, Failure modes, Corrosion damaged models, Thickness loss data

\section{INTRODUCTION}

To produce steel, iron ores must be processed. During the process of metal extraction, it consumes a large amount of energy to separate the metal from the ore. Large amounts of energy are consumed in the manufacturing of metals. This energy is essentially stored in the metal. Because of the fact that all configurations in nature tend to spontaneously change to lower states of energy, refined metal will deteriorate or corrode (Fontana [1]).

Based on the environment, type of steel, type of structure, and other related parameters there are five main forms of corrosion which can affect a steel structure. The most prevalent form is a general loss of surface material; this condition will lead to the gradual thinning of members. Pitting corrosion also involves loss of material at the surface. However, it is restricted to a very small area. Galvanic corrosion occurs when two dissimilar metals are electrochemically coupled. Such situations may occur at bolted or welded connections. Galvanic corrosion can be local, leading to pit formation. Crevice corrosion occurs in small confined areas, such as beneath peeling paint or between faying surfaces (Fontana [1]; Kayser [2]).

Steel structures can be affected by corrosion in many ways. The main effects can be loss of material from the surface, which leads to thinner sections. Section loss due to uniform corrosion may take place over a large area of a structural member. The loss of material due to uniform corrosion results in the reduction of section properties of a member, such as cross sectional area, moment of inertia, section modulus, radius of gyration and etc., thus causing a reduction in the carrying capacity of the structure. At severe levels of corrosion, the ultimate capacity of a steel member may fall below the service loads. Also it should be pointed out that the mode of failure due to loss of material can be changed (Sharifi and Rahgozar [3-7]). Corrosion damage must be carefully appraised and evaluated. In some cases, immediate repair or closure is necessary while in other cases, the conditions created by corrosion can be tolerated (Kulicki et al. [8]). It has been pointed out by Czarnecki and Nowak [9] that corrosion can lead to cracking (fracture), yielding or bucking of members. This can result in stress concentration, changes in geometric parameters, and a build-up of the corrosion products. These parameters are critical for the member's ability to resist load effects. 
The effects of both uniform and pitting corrosion on load-carrying capacity and reliability of corrosion damaged steel box-girder bridges has been investigated by Sharifi and Paik [10,11] and Sharifi [12], respectively.

The effect of corrosion on structural strength is not yet clear. Further investigation is necessary to clarify how the corrosion affects strength of beams. When beam strength is considered, (1) collapse strength (no buckling), (2) lateral-distortional buckling strength, (3) local buckling strength, (4) shear strength of web plates and (5) web crippling strength under concentrated loading etc. are important factors (Nethercot [13]).

It is possible to establish a relationship between the remaining capacities of various failure modes (moment, shear, lateral torsional buckling, bearing ...) and the loss of thickness for a special member. This approach can form the basis to derive a relationship between the magnitude of corrosion defects and the corresponding remaining capacity. For a particular failure mode of a beam, if the percentage remaining capacity is plotted against the percentage loss of thickness, it will be obtained a curve that gives the relationship between them. In this paper steel I-beams with uniform corrosion are used to calculate their remaining capacity. The overall aim of this paper is to consider remaining capacity of corroded steel I-beams using thickness loss information provided by visual inspection or measurements. The results of this study can be used for a better prediction of the service life (remaining capacity) of deteriorating I-beams.

\section{SPECIMENS OF CORRODED STEEL BEAMS}

Three same steel I-beams were removed from the site where all specimens were in a severely corroded condition (nearly 40 years old). The thicknesses of these beams were measured by an instrument which was designed especially for this purpose. The instrument, which was used together with a depth gauge, is shown in Figure 1.

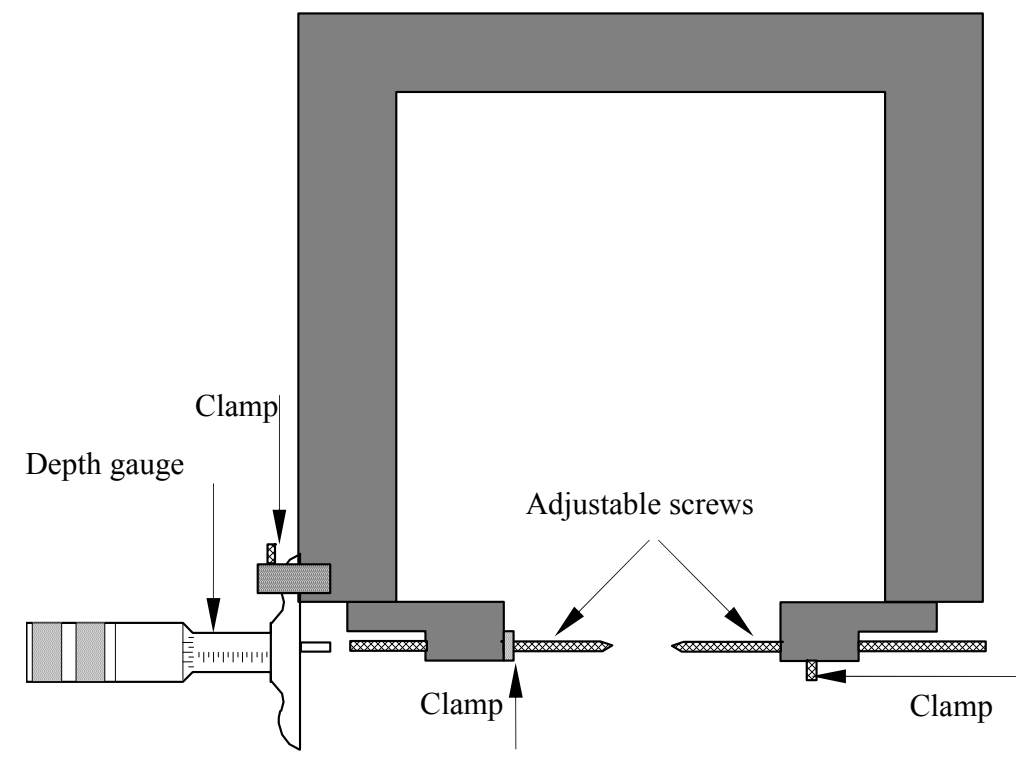

Figure 1. Instrument Used for Thickness Measurements of Sample Beams

As many readings as possible (up to 150 readings for each beam) were taken in order to increase the accuracy of the measurements. Average measurements of the thicknesses of each beam are shown in Table 1. The loss of thickness on average was more significant in the flanges than in the webs. 
Table 1. Average Measured Thicknesses of Corroded Beams ([Rahgozar [14])

\begin{tabular}{lllll}
\hline Element & New & Beam 1 & Beam 2 & Beam 3 \\
\hline Average thickness of top flange & 10.20 & 7.45 & 7.81 & 7.23 \\
\hline Average thickness of bottom flange & 10.20 & 5.62 & 5.85 & 4.84 \\
\hline Average thickness of top and bottom flanges & 10.20 & 6.54 & 6.83 & 6.04 \\
\hline $\begin{array}{l}\text { Average thickness loss of top and bottom } \\
\text { flanges }\end{array}$ & 0.00 & 3.66 & 3.37 & 4.16 \\
\hline $\begin{array}{l}\text { Percentage average thickness loss of top and } \\
\text { bottom flanges }\end{array}$ & 0.00 & $35.9 \%$ & $33.3 \%$ & \multirow{2}{*}{$40.8 \%$} \\
\hline Average thickness of upper part of web $\left(0.75 h_{w}\right)$ & 6.10 & 5.63 & 5.74 & 5.45 \\
\hline Average thickness of lower part of web $\left(0.25 h_{w}\right)$ & 6.10 & 3.16 & 4.32 & 3.18 \\
\hline Average thickness of web & 6.10 & 5.01 & 5.39 & 4.88 \\
\hline Average thickness loss of web $(\mathrm{mm})$ & 0.00 & 1.09 & 0.71 & 1.22 \\
\hline Percentage average thickness loss of web & 0.00 & $17.8 \%$ & $11.7 \%$ & $20.0 \%$ \\
\hline Note: $h=$ depth of web, all measurements are in millimeters & & & \\
\hline
\end{tabular}

\section{CORROSION MODEL DEVELOPMENT}

It has been pointed out by Kayser and Nowak [15] that severe corrosion may take place at the bottom one quarter of the web. Therefore the top surface of the bottom flange and the bottom part of the web are the regions where severe corrosion may take place, as shown in Figures 2. Corrosion also takes place in the top flange and the top part of the web but the loss is much less as compared to that of the web's bottom part.

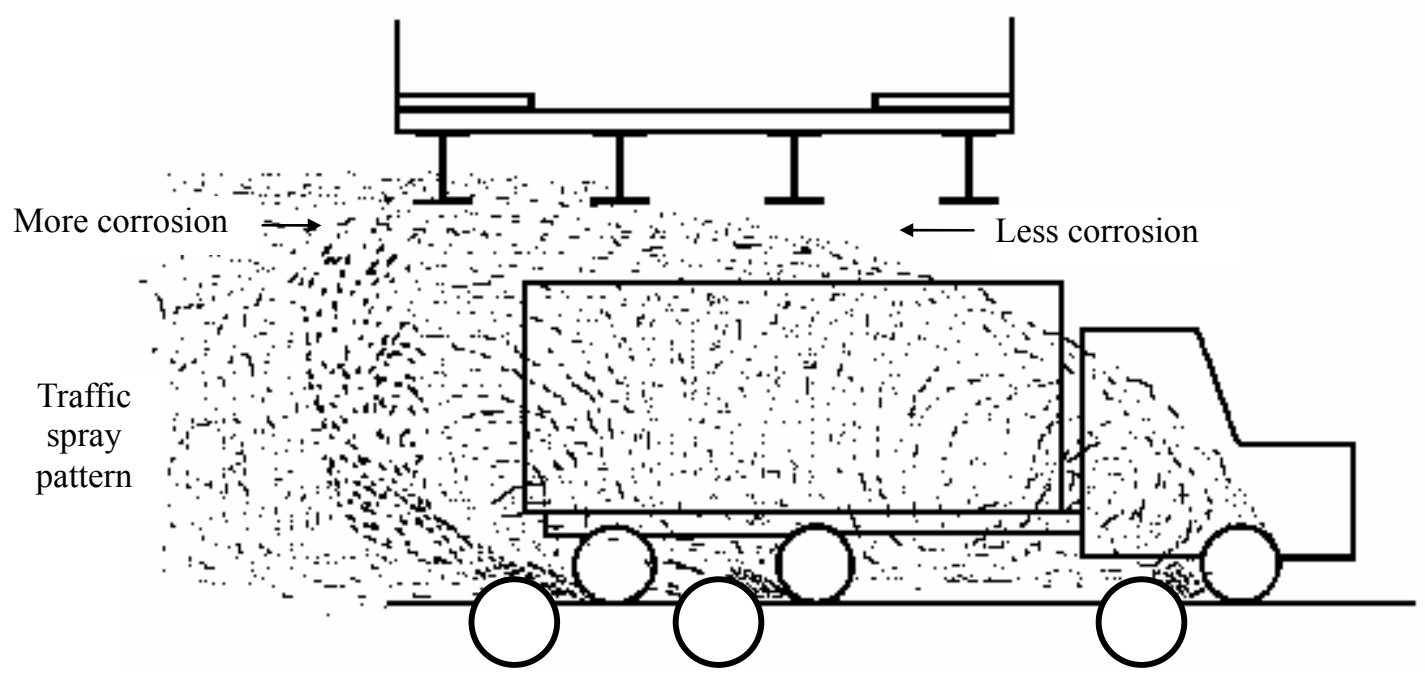

Figure 2(a) The Traffic Spray Accumulation on Girder Flanges and Webs 


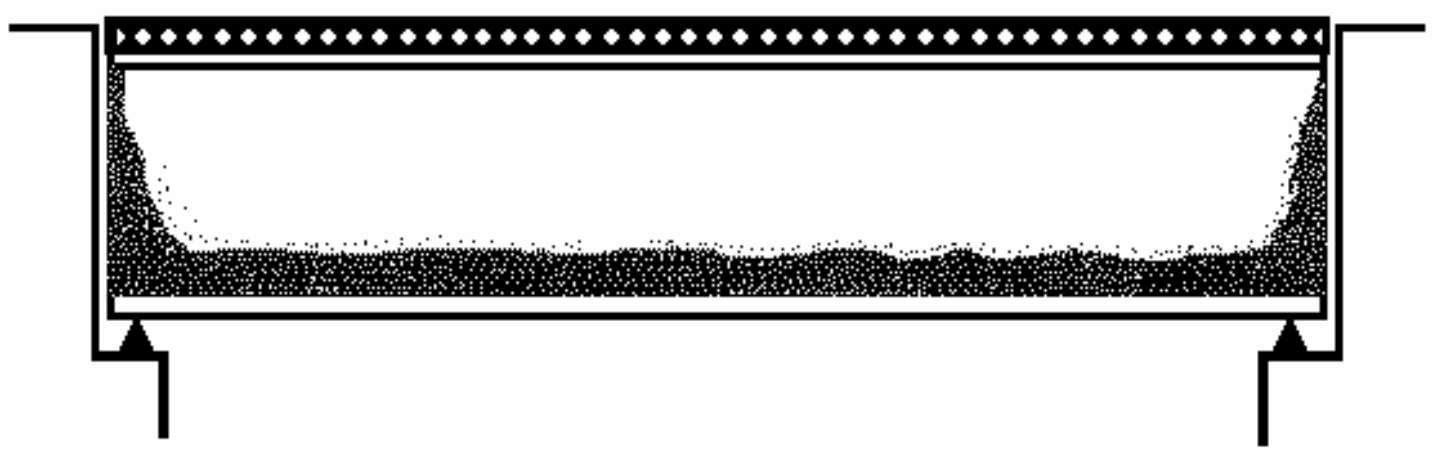

Figure 2(b). Typical Locations where Corrosion can Occur on a Steel Girder Bridge

The development of corrosion model mainly requires the information on the locations where corrosion normally occurs and the types of corrosion damage of steel members. The locations where corrosion occurs were discussed earlier. Using this information, corrosion model were considered by reducing the thickness of the sections. The model which is shown in Figure 3 is as follow:

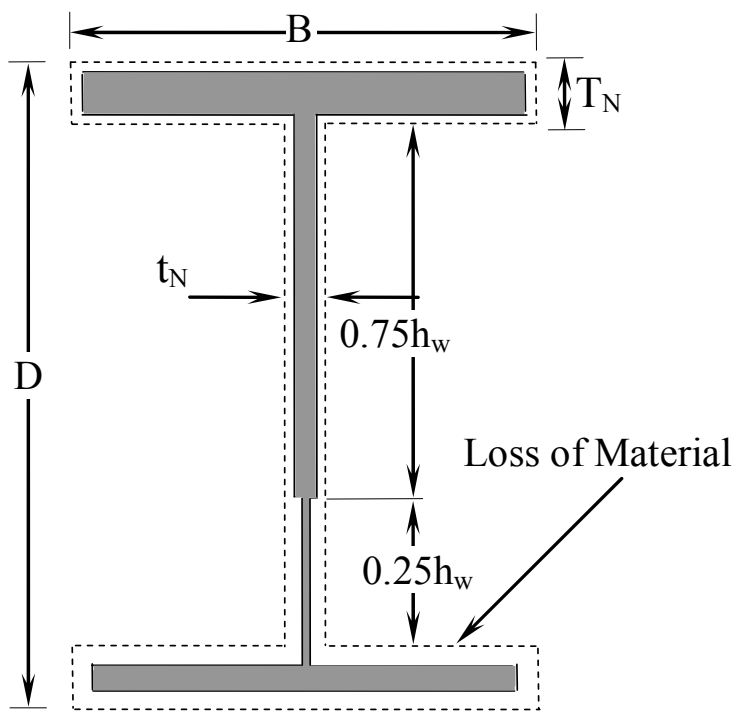

\section{Loss of Material}

Top flange

Upper part of the web

$\left(0.75 h_{w}\right)$

Lower part of the web

$\left(0.25 h_{w}\right)$

Bottom flange

where $\eta=\% L F T / 100$
$0.7 \eta T_{N}$

$0.25 \eta t_{N}$

$1.25 \eta t_{N}$

$1.3 \eta T_{N}$

Figure 3. Corrosion Model Simulated By Reducing the Thickness of Elements

Thickness of the top flange $=T_{N}(1-0.7 \eta)$

Thickness of the bottom flange $=T_{N}(1-1.3 \eta)$

Average thickness of the flanges $T_{c}=T_{N}(1-\eta)$

Thickness of the upper part of the web $\left(0.75 h_{w}\right)=t_{N}(1-0.25 \eta)$

Thickness of the lower part of the web $\left(0.25 h_{w}\right)=t_{N}(1-1.25 \eta)$

Average thickness of the web, $t_{c}=t_{N}(1-0.5 \eta)$

where $\eta=\eta_{F}=2 \eta_{W}$.

The thickness loss of flanges and web were in similar proportion to the thickness loss of the samples of corrosion damaged beams obtained from a chemical plant (Table 1). The measured thicknesses of these beams are given in Table 1. It can be established from Table 1 that the thickness loss of the bottom flange of sample beams is approximately twice as that of the loss of the 
top flange. The thickness loss of the lower part of the web $\left(0.25 h_{w}\right)$ is nearly five times as that of the upper part of the web $\left(0.75 h_{w}\right)$. For two sample beams the average thickness loss of the web is approximately half of that of the average loss of the flanges.

\section{REVIEW OF EXISTING FORMULAE FOR DIFFERENT FAILURES OF A STEEL BEAM}

As already noted when beam strength is considered, (1) collapse strength (no buckling), (2) local buckling strength, (3) shear strength of web plates, (4) lateral-distortional buckling strength, and (5) web crippling strength under concentrated loading are important factors (Nethercot [13]). Therefore, here the abovementioned failures will be investigated as following:

\subsection{Moment Strength (No Buckling)}

The effect of shear force $\left(F_{v}\right)$ is to reduce the plastic moment capacity but the reduction for an I-section is small for $F_{v}<0.6 P_{v}$, where $p_{v}$ is the shear capacity. For low shear load $\left(F_{v}<0.6 P_{v}\right)$ the moment capacity, $M_{c}$, is as follows:

For plastic and compact sections:

$M_{c}=p_{y} S \quad$ but $<1.2 P_{y} Z_{C}$

For semi-compact sections

$M_{c}=p_{y} Z$

For slender sections

$M_{c}=p_{y} Z$

where

$p_{y}$ is the design strength (reduced for slender sections-BS 5950 [16]), $S$ and $Z$ are the plastic and the elastic modulus of the section about the relevant axis, respectively.

\subsection{Local Buckling Strength}

Structural steel members such as I-beams, columns, channels, are composed of connected elements (web to flanges) which, for the purpose of analysis and design, can be treated as flat plates. When compression forces are applied to opposite edges of a flange as shown in Figure 4, a theoretical critical stress can be evaluated indicating that the flange may buckle locally before the member as a whole becomes unstable or before the yield stress of the material is reached. Such a critical stress may be in either the elastic or inelastic range.

The resistance of an element to plate buckling depends on its geometry, its material properties and its external restraint conditions along the boundaries. For the case of flange buckling, the critical factor is found to be the ratio of the width of the outstand element of compression flange, $b=B / 2$, to the flange thickness, $T$ (Trahair et al. [17]).

The thin plate shown in Figure 4 is simply supported along both transverse edges and one longitudinal edge and is free along the other, which is subjected to compression forces as shown. When the applied forces are equal to the critical value, the plate can buckle by deflecting laterally out of its original plane as shown in Figure 4. The magnitude of this elastic critical compressive stress, $P_{c r}$, at which the plate buckles, is given by Timoshenko and Gere [18] as: 


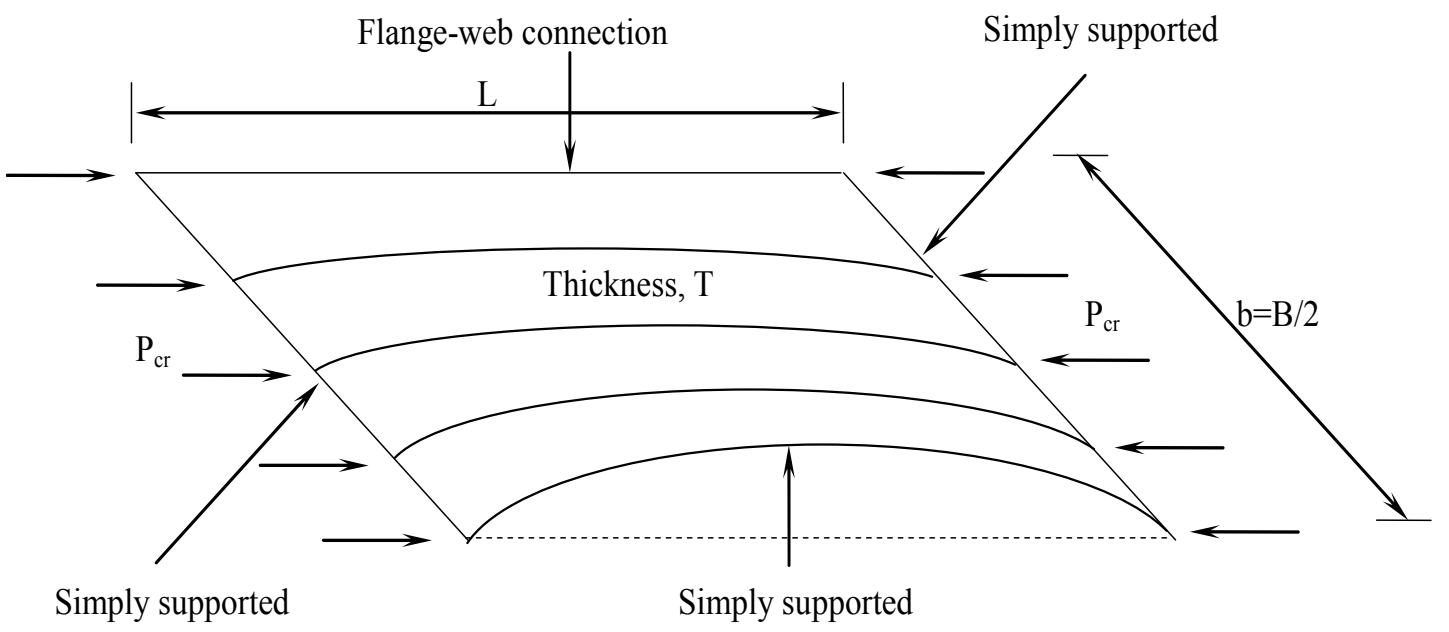

Figure 4. Buckled Shape of a Plate Free Along One Side

$P_{c r}=k \frac{\pi^{2} E}{12\left(1-v^{2}\right)(b / T)^{2}}$

where, $k$ is a buckling coefficient determined by a theoretical critical load analysis (Timoshenko and Gere [18]). It is a function of plate geometry and restraint conditions.

This elastic critical compressive stress was obtained by assuming that the buckled shape of the plate is in the form of a sinusoidal half-wave over the full length of the flange as shown in the Figure 5. When a member cross section is composed of various connected elements, lower bound of the critical stress can be determined by assuming, for each plate element, a simple support condition for each edge attached to another plate element or a free condition for any edge not so attached (Johnston [19]). In the case of a flange (by treating it as a plate), the restraint condition can be taken as simple support along the connection with the web and free at the other. In this case, the buckling coefficient, $k$, is approximated by Trahair et al. [17] as:

$k=0.425+\left(\frac{b}{L}\right)^{2}$

For long plate elements, which are used in most structural steel members, the length of the plate, $L$, can be taken as large or infinity and the buckling coefficient, $k$, can be taken as the minimum value of 0.425 . In this case, the elastic critical stress is equal to the yield stress, $p_{y}$, of steel for which $E=$ $205000 \mathrm{~N} / \mathrm{mm}^{2}$ and $v=0.3$ when the limiting $b / T$ ratio is as follows:

$b / T=16.9 \varepsilon$

where $\quad \varepsilon=\sqrt{\frac{275}{p_{y}}}$

If this $b / T$ ratio is exceeded, elastic buckling of the outstanding elements is predicted. However this $b / T$ ratio is not necessarily a conservative basis for design, since residual stresses and initial imperfections will have their greatest strength reducing influence precisely at the $b / T$ ratio found in 
this manner (Johnston [19]). BS 5950 [16] predicts elastic buckling of outstanding elements of rolled sections when the ratio, $b / T>9.5 \varepsilon$. BS 5950 [16] recommends a reduced design strength, $p_{y}$, when the ratio, $b / T>15 \varepsilon$ for slender cross sections.

\subsection{Shear Strength of Web Plates}

The web panel shown in Figure 5(a) is loaded in shear and the web is stiffened using stiffeners of length $a_{s}$. The thin flat plate of length, $a_{s}$, depth $d$, and thickness $t$ shown in Figure 5(b) is simply supported along all four edges. The plate is loaded in shear, distributed uniformly along its edges. When these stresses are equal to the elastic buckling value, $\tau_{c r}$, then the plate will buckle laterally out of its original plane into an adjacent position (Trahair et al. [17]).

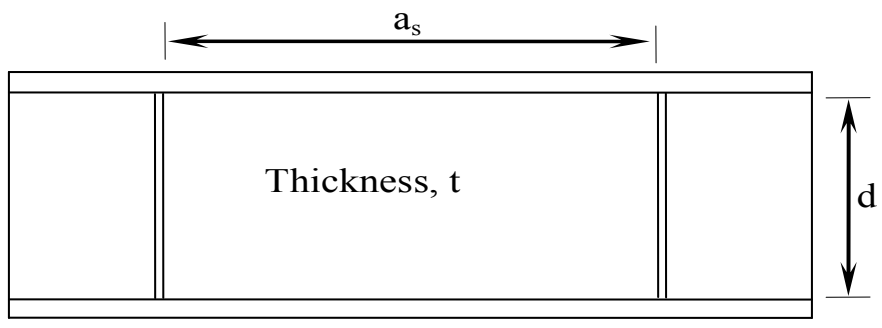

(a) Geometry of Web Panel

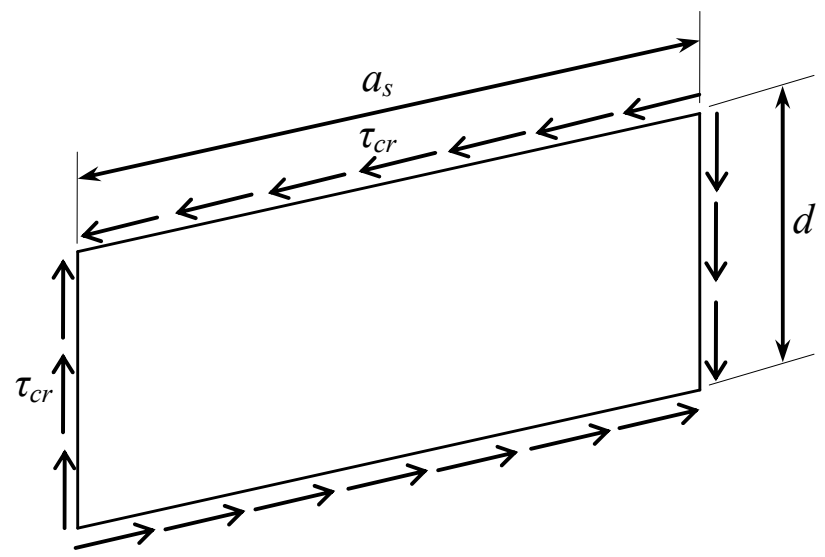

(B) Buckled Pattern of a Simply Supported Plate in Shear

Figure 5. Web Buckling Due to Pure Shear

The elastic critical shear stress $\tau_{c r}$, at which the web buckles can be predicated from plate buckling theory and is given by Timoshenko and Gere [18] as:

$\tau_{c r}=k \frac{\pi^{2} E}{12\left(1-v^{2}\right)(d / t)^{2}}$

In which the buckling coefficient, $k$ is determined by a theoretical critical load analysis (Timoshenko and Gere [18]). It is a function of plate geometry and boundary conditions and is given by Johnston [19] as: 


$$
\begin{array}{ll}
k=4.00+\frac{5.34}{\left(a_{s} / d\right)^{2}} & \text { for } a_{s} / d \leq 1 \\
k=5.34+\frac{4.00}{\left(a_{s} / d\right)^{2}} & \text { for } a_{s} / d \geq 1
\end{array}
$$

If the numerical values for $v=0.3$ and $E=205000 \mathrm{~N} / \mathrm{mm}^{2}$ are substituted in to Equation (7), and further combined with Equation (8a) and (8b), then,

$$
\begin{array}{ll}
\tau_{c r}=\left(0.75+\frac{1.00}{\left(a_{s} / d\right)^{2}}\right)\left(\frac{995}{d / t}\right)^{2} \quad \text { for } a_{s} / d \leq 1 \\
\tau_{c r}=\left(1.00+\frac{0.75}{\left(a_{s} / d\right)^{2}}\right)\left(\frac{995}{d / t}\right)^{2} \quad \text { for } a_{s} / d \geq 1
\end{array}
$$

The shear stresses in many structural members are transmitted by unstiffened webs, for which the aspect ratio, $a / d$, is large and assumed infinity. Therefore, for unstiffened webs, using Equation (9b), $\tau_{c r}$ can be given as:

$$
\tau_{c r}=\left(\frac{995}{d / t}\right)^{2}
$$

Using maximum distortion strain energy theory (Von-Mises yield criterion); it can be shown that the yield stress in shear, $\tau_{y}$, is equal to $p_{y} / \sqrt{3}\left(\approx 0.6 p_{y}\right)$, where $p_{y}$ is the design strength of the web (Trahair et al. [17]). Stocky unstiffened webs in steel beam yield in shear before they buckle elastically. When a web panel yields, the critical shear stress is equal to the yield stress in shear.

i.e. $\tau_{c r}=\frac{p_{y}}{\sqrt{3}}$

Using Equations (10) and (11), the limiting ratio of $d / t$ for web yielding in shear can be given as:

$d / t=79 \varepsilon$

where

$\varepsilon=\sqrt{275 / p_{y}}$

A stocky unstiffened web in an I-section beam subjected to pure shear loading is shown in Figure 6(a). The web behaves elastically in shear until yielding starts at $\tau_{y}=p_{y} / \sqrt{3}$, yielding continues as the section undergoes increasing plastification until the web has yielded fully in shear. Because the shear stress distribution at first yield is nearly uniform, the nominal first yield and fully plastic loads are nearly equal, and the shear shape factor is usually very close to 1.0. Stocky unstiffened webs in steel beams reach first yield before they buckle elastically, hence their strengths are determined by the shear stress $\tau_{y}$, as indicated in Figure 6. 
Thus the resistance of a stocky web in a flanged section for which the shear shape factor is near unity is closely approximated by the web plastic shear resistance:

$V_{w}=d t \tau_{y}$

When the depth to thickness ratio $d / t$ of a long unstiffened steel web exceeds $79 \sqrt{275 / p_{y}}$, its elastic buckling shear stress $\tau_{c r}$, is less than the shear yield stress.

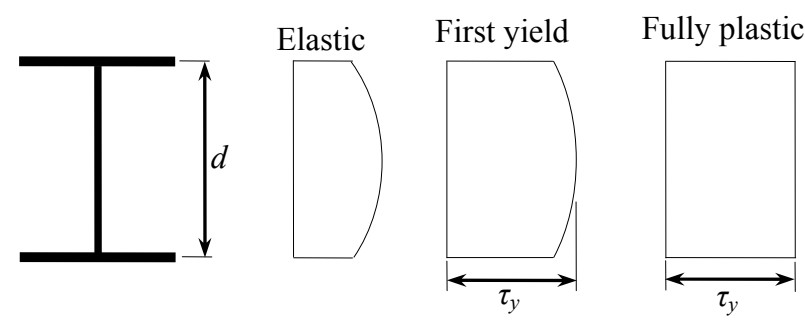

$\begin{array}{ll}\text { (a) I-section } & \text { (b) Shear stress distributions }\end{array}$

Figure 6. Plastification of an I-Section Web in Shear

The design shear force $F_{v}$ on a web for which the shear stress is approximately uniform must satisfy $F_{v} \leq P_{v}$, in which $P_{v}$ is the uniform shear capacity. The uniform shear capacity of a stocky web of area $A_{v}$ is given by:

$P_{v}=0.6 p_{y} A_{v}$

Which is very close to $d t \tau_{y}\left(\approx 0.58 A_{v} p_{y}\right)$ given for the fully plastic shear capacity, where $d$ is the depth of the web and $t$ the web thickness. An I-section web is classified by BS 5950 as stocky when its depth to thickness ratio satisfies $d /(t \varepsilon) \leq 70$ for a hot-rolled beam (the web of all British universal sections of S275 or S355 steel are stocky), and when $d /(t \varepsilon) \leq 62$ for a welded plate girder, otherwise it is classified as slender. Not that the value 62 is less than the value of 79 which developed earlier (Equation (12)) on limiting slenderness when elastic buckling $\tau_{c r}$ is equal to shear yield stress $\tau_{y}$ (Trahair et al. [17]).

BS 5950 recommends that when $d / t$ exceeds $62 \varepsilon$ the web should be checked for sighs of shear buckling. The code uses notation $q_{e}$ instead of $\tau_{c r}$ for the elastic critical shear stress. It also identifies three modes of behavior for webs.

The first mode is where the web strength is governed by its ultimate yield strength, i.e. $p_{y} / \sqrt{3}$, the third is where the capacity is solely governed by the elastic critical shear stress, $q_{c r}$, and the intermediate stage is where an interaction occurs between the first and third modes. The divisions between the three modes are quantified by equivalent web slenderness factor, $\lambda_{w}$, which is given by Trahair et al. [17]:

$\lambda_{w}=\left(p_{v} / q_{e}\right)^{0.5}$

where

$p_{v}=0.6 p_{y}$ 
Code (BS 5950) gives the critical shear strength, $q_{w}$, of a web panel as follows:

For $\lambda_{w} \leq 0.8, q_{w}=p_{v}$

For $0.8<\lambda_{w}<1.25, q_{w}=\left[\left(13.48-5.6 \lambda_{w}\right) / 9\right] p_{v}$

For $\quad \lambda_{w} \geq 1.25, q_{w}=\left(0.9 / \lambda_{\mathrm{w}}\right) p_{v}$

when no stiffener is provided, using Equations (10) and (16) it can be shown that,

For $\quad \lambda_{w}=0.8$, then $d / t=62 \varepsilon$

For $\lambda_{w}=1.25$, then $d / t=97 \varepsilon$

When an I-beam is subjected to bending, most of the applied shear force is resisted by the web. Web thickness of a corroded beam can remain uniform at initial stages of corrosion. In sections, where web thickness does not vary significantly due to corrosion, average web thickness may be used for evaluating the shear capacity. When depth to thickness ratio, $d / t$, exceeds $62 \varepsilon$ the web should be checked for shear buckling in accordance with BS 5950 [16].

\subsection{Lateral Distorsional Buckling Strength}

The compression flange of an I-beam acts like a column and will buckle sideways if the beam is not sufficiently stiff or the flange is not restrained laterally. The load at which the beam buckles can be much less than that causing the full moment capacity to develop. For an idealized perfectly straight beam, there are no deformations normal to the loading plane until the applied moment reaches a critical value $M_{E}$, less than the moment capacity. At this point the beam buckles by deflecting laterally and twists as shown in Figure 7. These two deformations are interdependent, when the beam deflects laterally; the applied moment exerts a component torque about the deflected longitudinal axis which causes the beam to twist. This behavior, which is important for long unrestrained I-beams, is called lateral torsional buckling.

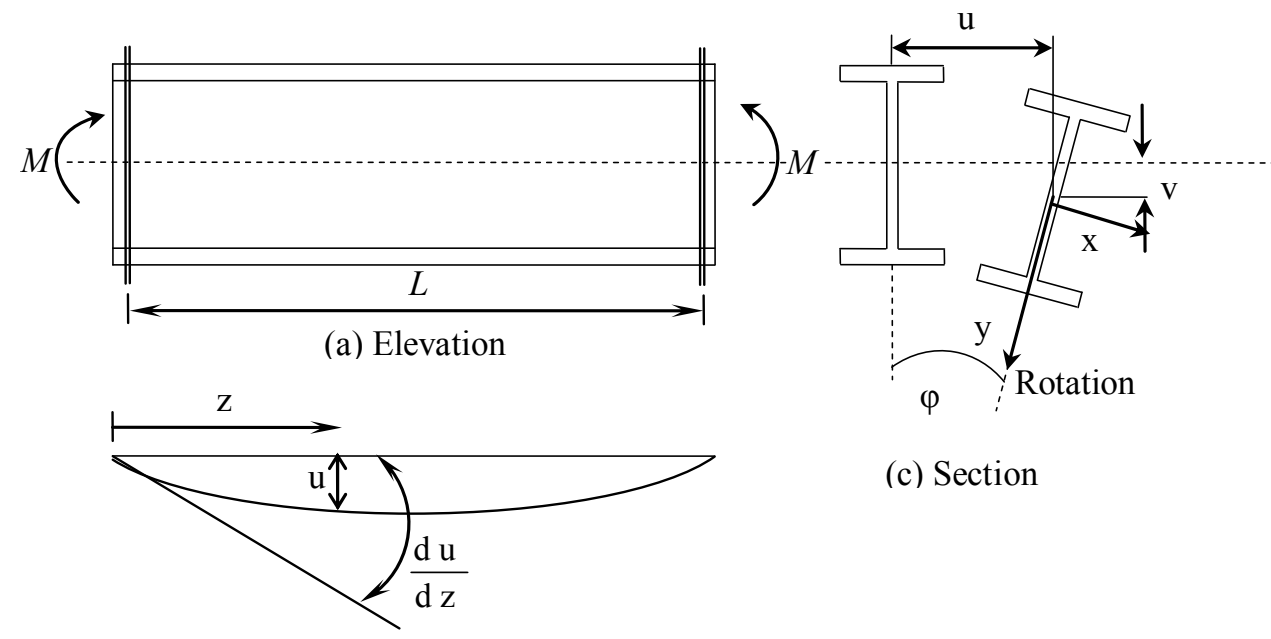

(b) Plan on the longitudinal axis

Figure 7. Lateral Torsional Buckling of a Simply Supported I-Beam 
A perfectly straight beam which is loaded by equal and opposite end moments is shown in Figure 7. The beam is simply supported at its ends so that lateral deflection and twist rotation are prevented, while the flange ends are free to rotate in horizontal planes. Elastic theory is used to set up equilibrium equations that equate external disturbances to the lateral bending and torsional resistance of the beam. The solution of these equations for the elastic critical moment was given by Timoshenko and Gere [18] as:

$M_{E}=\frac{\pi}{L}\left(E I_{y} G J\right)^{1 / 2}\left(1+\frac{\pi^{2} E I_{w}}{L^{2} G J}\right)^{1 / 2}$

where, $M_{E}$ is elastic critical buckling moment, $E I_{y}$ is the minor axis flexural rigidity, $G J$ is the torsional rigidity, $E I_{w}$ is the warping rigidity of the beam, and $L$ is the beam length, Equation (20) shows that the resistance to buckling depends on the geometric mean of the flexural resistance $\left(\pi^{2} E I_{y} / L^{2}\right)$ and the torsional resistance $\left(G J+\pi^{2} E I_{w} / L^{2}\right)$.

The magnitude of the critical moment given by Equation (20) does not depend on the major axis flexural rigidity $E I_{x}$ of the beam in the vertical plane. This conclusion is obtained as a result of the assumption that the deflections in the vertical plane are small as shown in Figure 7, which is justifiable since the flexural rigidity $E I_{x}$ is much greater than the rigidities $E I_{w}$ and $E I_{y}$. If the rigidities are of the same order of magnitude, the effects of bending in the vertical plane should be considered (Timoshenko and Gere [18]). The equation for the elastic critical buckling moment, which includes the effect of major axis bending, is given by Martin et al. [20] as:

$M_{E}=\frac{\pi}{L}\left(\frac{E I_{y} G J}{\gamma}\right)^{1 / 2}\left(1+\frac{\pi^{2} E I_{w}}{L^{2} G J}\right)^{1 / 2}$

Where $\gamma$ is the correction factor, which is just less than unity for most beam sections, and is given by, $\gamma=1-\frac{I_{y}}{I_{x}}$

\subsection{Web Bearing Strength}

Plate elements (e.g. webs) are subjected to bearing stresses by concentrated loads or locally distributed edge loads (reactions from supports or other members) as shown in Figure 8. For example, a concentrated load applied to the top flange of a beam induces local bearing stresses in the web immediately beneath the load. When the load reaches its critical value, the web crushes (cripples) by combined compression and folding directly under the load. 


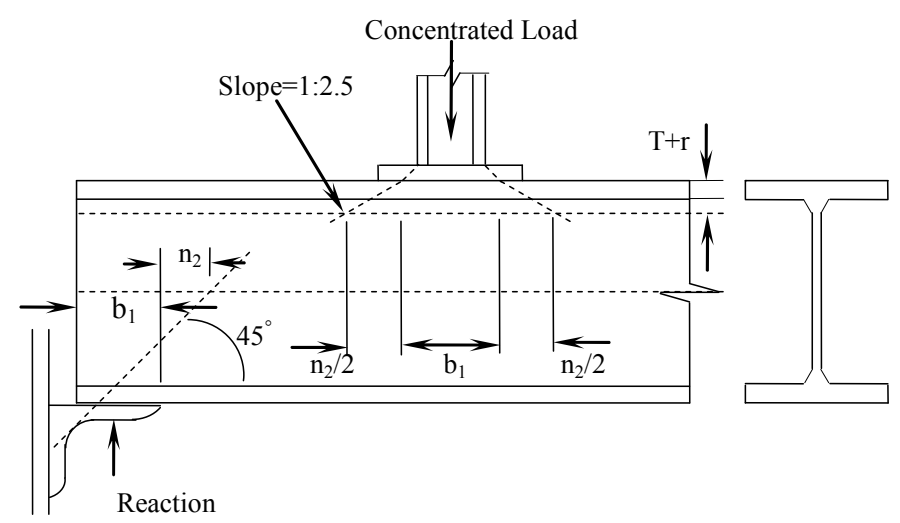

Figure 8. Effective Web Bearing Length to Resist Crushing

The ultimate bearing strength of a thick web depends on its design strength, $p_{y}$. although yielding first occurs under the centre of the bearing plate, general yielding does not takes place until the applied load is large enough to cases yielding of a web area defined by a dispersion of the applied load is large enough the flange. Even at this load the web does not collapse catastrophically, and some further yielding and redistribution is possible (Trahair et al. [17]).

Where point loads or reactions from supports or other members are applied to a beam as shown in Figure 8 then the web should be checked for bearing stresses. The web bearing strength, $P_{w b g}$, is given by

$P_{w b g}=\left(b_{t}+n_{2}\right) t p_{y}$

where

$b_{t}$ is the stiff bearing length,

$n_{2}$ is the length obtained by the slope 1:2.5 dispersion through the flange and can be taken as follows: $n_{2}=2 \times 2.5(T+r)$ for forces applied through a flange by loads or reactions in the length between the ends and

$n_{2}=2.5(T+r)$ for forces applied through a flange by loads or reactions at the ends,

$t$ is the thickness of the web and,

$p_{y}$ is the design strength of the web.

The code recommends that if the force applied through a flange by loads or reactions exceeds the local capacity of the web at its connection to the flange, then bearing stiffeners should be provided.

\section{INVESTIGATION OF CORROSION EFFECTS ON RESIDUAL STRENGTH OF STEEL I-BEAMS}

To demonstrate the effect of corrosion on residual capacity, a steel beam which has been subjected to flexural bending is considered. It is mentioned that a steel beam can fail in different ways depending on its dimension and loading. The principle modes of failure are:

1. Flexural bending

2. Shear failure

3. Lateral distorsional buckling

4. Bearing failure of the web 
As mentioned earlier, loss of material due to corrosion not only reduces the section properties and hence the carrying capacity of a member, but also it can change the mode of failure from one to another depending on the rate and place of corrosion. The loss of thickness in the flanges and web due to corrosion, results in reduction in the capacity. For example, an element may become slender due to corrosion during its service life and local buckling may prevent the development of full plastic moment in such cases. To verify these effects of corrosion, an investigation has been carried out using the corrosion model shown in Figure 3 and the foregoing approaches on the steel structures members. A section of arbitrary dimension was used to illustrate this phenomenon.

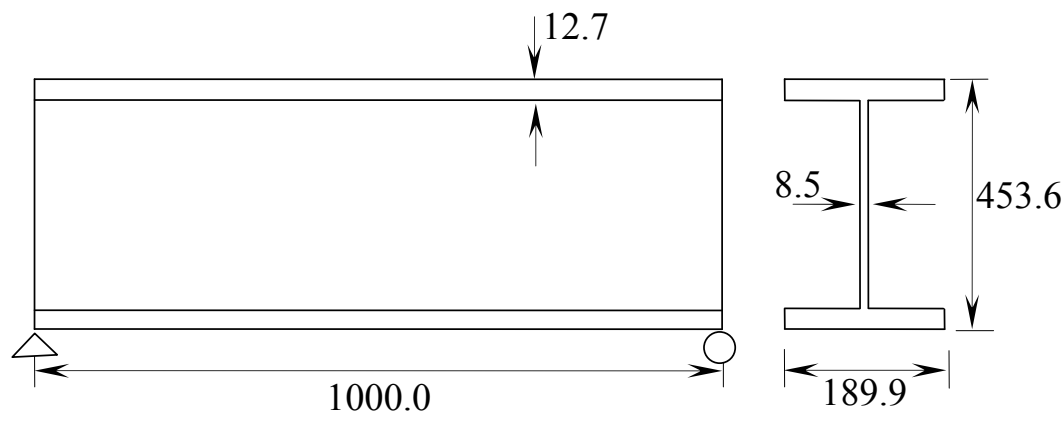

Figure 9. Dimensions of I-Beam (All Measurements are in $\mathrm{mm}$ )

It was assumed that the beam is $1000 \mathrm{~mm}$ long and simply supported at the ends. It was also assumed that the beam carries a central point load. The dimensions of the beam are shown in Figure 9. The theories given in BS 5950 [16] were used for the assessment of the capacities with regard to the failure mechanisms mentioned above. The results, obtained from the above analysis, are plotted in Figure 10.

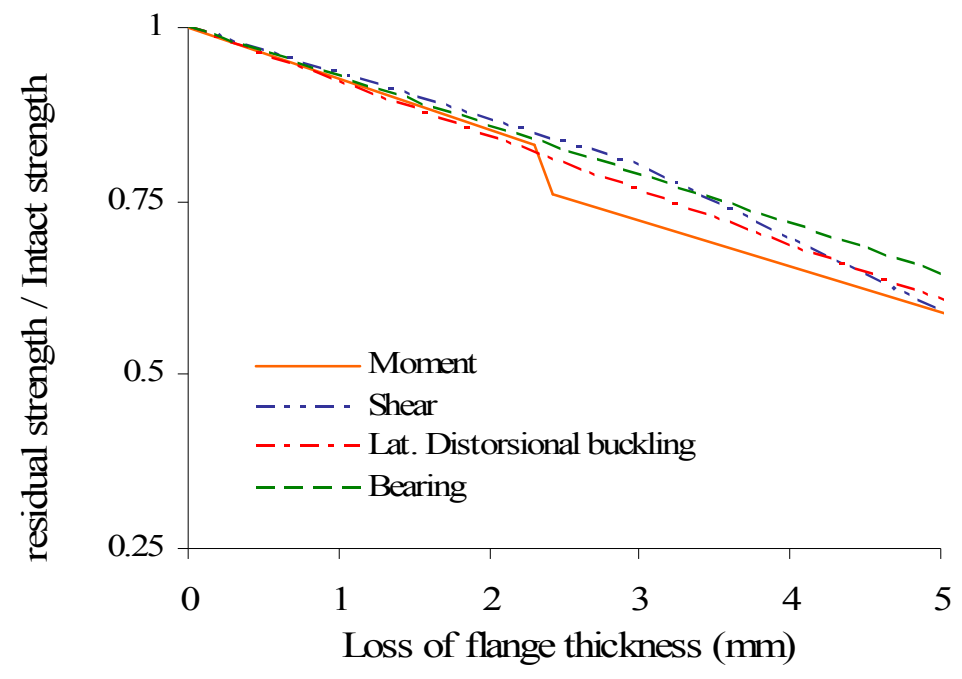

Figure 10. Remaining Capacities of a Corroded I-Beam

As it can be seen from Figure 10 that the reduction in capacities is approximately linear. Moreover, at a certain point there is a sudden drop in the moment and shear capacities. This happens when the class of the compression flange or web is changed from one to another due to loss of thickness. When this happens local buckling of flange or web may prevent the development of full plastic moment and shear. It is observed from these analyses that the rate of reduction of shear capacity is greater than of the bending capacities. The lateral distorsional buckling is the critical failure mode at the early stages of corrosion. 


\section{CONCLUSIONS}

It is clear that the important result of corrosion damage is reduction of the section properties and hence the carrying capacity of a member in during of service life. It can also change the mode of failure from one to another. In other word by increasing the age of steel I-beam, not only all capacities will be decreased but also the mode of failure may change. The analysis of existing structures may differ from the analysis of structures under design, especially if there is damage by corrosion. Some of the assumptions made in design may no longer be true and other failure mechanisms may become significant. It can be found from Figure 10 that the critical failure mode changes from lateral distorsional buckling to local buckling of flanges. The lateral distorsional buckling failure mode governs the flexural member in its early stages. Then, after several years of corrosion, the local buckling of flanges becomes the critical failure mode.

\section{ACKNOWLEDGEMENTS}

The author is pleased to acknowledge the Vali-e-Asr University of Rafsanjan support.

\section{REFERENCES}

[1] Fontana, M.G., "Corrosion Engineering”, McGraw Hill Book Company, New York, Third Edition, 1987.

[2] Kayser, J.R., "The Effects of Corrosion on The Reliability of Steel Girder Bridges", PhD thesis, Department of Civil Engineering, University of Michigan, 1988.

[3] Sharifi, Y. and Rahgozar, R., "Evaluation of the Remaining Shear Capacity in Corroded Steel I-Beams", International Journal of advanced Steel Construction, 2010, Vol. 6, No. 2, pp. 803-816.

[4] Sharifi, Y. and Rahgozar, R., "Remaining Moment Capacity of Corroded Steel Beams", International Journal of Steel Structures, 2010, Vol. 10, No. 2, pp. 165-176.

[5] Sharifi Y. and Rahgozar R., "Simple Assessment Method to Estimate the Remaining Moment Capacity of Corroded I-Beam Sections", Scientia Iranica Journal, 2010, Vol. 17, No. 2, pp. 161-167.

[6] Sharifi Y. and Rahgozar R., "Evaluation of the Remaining Lateral Torsional Buckling Capacity in Corroded Steel Beams", Journal of Zhejiang University Science A, 2010, Vol. 11, No. 11, pp. 887-897.

[7] Sharifi, Y. and Rahgozar, R., "Fatigue Notch Factor in Steel Bridges Due to Corrosion", Archives of Civil and Mechanical Engineering, 2009, Vol. IX, No. 4, pp. 75-83.

[8] Kulicki, J.M., Prucs, Z., Sorgenfrei, D.F. and Mertz, D.R., "Guidelines for Evaluating Corrosion Effects in Existing Steel Bridges", National Cooperative Highway Research Program, Report 333, Transportation Research Board, National Research Council, Washington, D.C; 1990.

[9] Czarnecki, A.A. and Nowak, A.S., "Time-Variant Reliability Profiles for Steel Girder Bridges", Structural Safety, 2008, Vol. 30, No. 49-64.

[10] Sharifi, Y. and Paik, J.K., "Ultimate Strength Reliability Analysis of Corroded Steel-box Girder Bridges", Thin-Walled Structures, 2011, Vol. 49, No. 1, pp. 157-166.

[11] Sharifi, Y. and Paik, J.K., "Environmental Effects on Ultimate Strength Reliability of Corroded Steel Box Girder Bridges", Structural Longevity, 2009, Vol. 2, No. 2, pp. 81-102.

[12] Sharifi, Y. "Reliability of Deteriorating Steel Box-Girder Bridges under Pitting Corrosion", International Journal of advanced Steel Construction, 2011, Vol. 7, No. 3, pp. 220-238. 
[13] Nethercot, D.A., "Limit States Design of Structural Steelwork", 3rd ed. Spon Press, London, UK, 2001.

[14] Rahgozar, R., "Remaining Capacity Assessment of Corrosion Damaged Beams using Minimum Curves", Journal of Constructional Steel Research, 2009, Vol. 65, pp. 299-307.

[15] Kayser, J.R. and Nowak, A.S., "Capacity Loss Due to Corrosion in Steel-Girder Bridges", Journal of Structural Engineering, ASCE, 1989, 115, pp. 1525-1537.

[16] BS 5950, "Structural use of Steel Work in Building: Part 1, Code of Practice for Design in Simple and Continuous Construction, Hot rolled Sections", British Standard Institution, London, 1985.

[17] Trahair, N.S., Bradford, M.A. and Nethercot D.A, "The Behavior and Design of Steel Structures to BS5950", Third Edition-British, London, Spon Press, Taylor \& Francis Group, 2001.

[18] Timoshenko, S.P. and Gere, J.M. "Theory of Elastic Stability", McGraw-Hill Book Company, 1961.

[19] Johnston, B.G. "Guide to Stability Design Criteria for Metal Structures", Third Edition, John Wiley \& Sons, 1976.

[20] Martin L.H. and Purkiss, J.A. "Structural Design of Steelwork to BS 5950", First Edition, Edward Arnold, London, 1992. 